\title{
Ischemic Stroke: New Neuron Recovery Approach with Mesenchymal and Neural Stem Cells
}

\author{
Angliana Chouw ${ }^{1,2}$, Rina Triana ${ }^{1,3}$, Nurrani Mustika Dewi ${ }^{1,3}$, Siska Darmayanti ${ }^{1,3}$, \\ Miftakh Nur Rahman ${ }^{1,3}$, Ardian Susanto ${ }^{1,3}$, Bayu Winata Putera ${ }^{2}$, Cynthia Retna Sartika² \\ ${ }^{1}$ Magister Program of Clinical Pharmacy, Faculty of Pharmacy, Padjajaran University, Bandung, Indonesia \\ ${ }^{2}$ Prodia Stem Cell, Jakarta, Indonesia \\ ${ }^{3}$ Prodia Clinical Laboratory, Jakarta Indonesia
}

Stroke is a leading cause of death and long-term disability. This due to the ischemic event that cause by embolism of blockage blood flow. Thrombolytic agent plasminogen activator (tPA) is the only treatment approved by FDA. However, the used of tPA is limited to the short time window period. Neural stem cells (NSCs) show the potential to repair neuronal damage naturally after stroke. However, isolating NSCs is a challenging process due to the limitations of the method and its invasiveness. Some studies that had used mesenchymal stem cell (MSCs) as the main source of stem cell for therapy show that MSCs have the potency to differentiate into NSCs. in vitro, a differentiation process from MSC to NSC has been developed by combining the supplement or growth factor needed in the culture media.

Keywords: stem cells, neuron stem cell, mesenchymal stem cell, stroke, trans-differentiation

\section{Introduction}

A stroke, also called a 'brain attack', occurs when a clot blocks the blood supply to the brain or when a cerebral blood vessel bursts, and is a leading cause of serious longterm disability. ${ }^{1}$ There are two types of stroke, hemorrhagic stroke and ischemic stroke. ${ }^{2,3}$ Ischemic stroke occurs due to cerebral vascular obstruction, thus limiting the blood supply containing vital oxygen and substrate to neurons (hypoxia). ${ }^{4}$ A small percentage, caused by rupture of the brain's blood vessels, is called a hemorrhagic stroke. ${ }^{5}$

Stroke kills almost 130,000 of the 800,000 Americans who suffer from it each year. ${ }^{6}$ In Indonesia, stroke is the number one killer, with a $15.4 \%$ prevalence in the population. Ischemic stroke accounted for most of the cases $(67.1 \%)$, while hemorrhagic strokes accounted for the remaining $32.9 \%$. Hypertension is the most common risk factor for both hemorrhagic (71.2\%) and ischemic stroke $(63.4 \%)^{7}$

A stroke requires immediate medical attention and care because damage to the brain evolves rapidly. In case of ischemic stroke, intravenous thrombolytic agents, which pharmacologically dissolve clots are used for an acute treatment. So far, tissue plasminogen activator (tPA) is the only Food and Drug Administration (FDA) approved drug for acute ischemic strokes and should be used within 4.5 hours from the onset of stroke symptoms. ${ }^{2,3}$

Date of submission: Dec 29, 2017

Last Revised: July 22, 2018

Accepted for publication: August 2, 2018

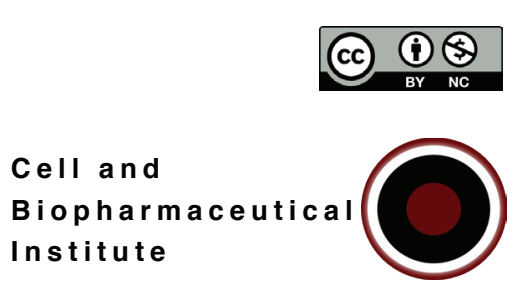

Corresponding Author:

Angliana Chouw

Magister Program of Clinical Pharmacy

Faculty of Pharmacy, Padjajaran University

Jl. Eijkman No.38, Bandung, Indonesia

E-mail: angliana@prostem.co.id 
Another stroke therapies is needed in order to improve outcomes for most of the stroke patients. As there is a second therapeutic time window for nerve regeneration that appeared days or weeks after stroke. ${ }^{4}$ Stem cell therapy using mesenchymal and neural stem cell shows potential as an alternative interventions for modifying disease therapy. In this article, we present a brief overview of how mesenchymal stem cell could be used directly or to be transdifferentiate into neural stem cell in in vitro.

\section{Stem Cell for Therapy}

Over the past decade, the improving field of stem cell biology has become a common concern among scientists because of its unique properties that potentially offer ideal solutions to many health problems, including stroke. ${ }^{8}$ Stem cell therapy has been reported to shown promising result in tissue regeneration and homeostasis after an injury. ${ }^{5}$ Stem cell therapy offers the promise of treating diseases and playing a role as an alternate source of biological material for cell restorative treatments, which currently have no or limited therapeutic options. ${ }^{9}$ Stem cells have the ability to develop into many different cell types, with each new cell capable of either remaining as a stem cell or differentiating into another cell type with a more specific function. ${ }^{8}$

In the process of neuron regeneration, it is beliefs that stem cell have two importants role. Stem cell is used to replace the dead cells to the injury, such as replacing the lost neurons in order for a new neuronal circuitry could be rebuild. The others role is through enhancing the exogenous stem cells to secrete trophic factors that will support the self repair systm of cell in the infarct area. This trophic factors could have effect for neuroprotection through antiinflammation, antioxidative, antiapoptosis, blood brain barrier protection dam promoting the angiogenesis dan neurogenesis. ${ }^{10,11}$ Due to inflamation after stroke event, injured cell will secrete tumor necrosis factor- $\alpha$ (TNF- $\alpha$ ), interleukin (IL)-1, and IL-6, which will increase microglia in the brain. ${ }^{12}$

There are two main sources of stem cells, namely embryonic stem cells (ESC) and adult stem cells (ASC). ESCs are cells isolated from the embryonic inner cell mass, which is formed in the early stage of embryonic development. They are pluripotent, genetically normal and able to proliferate extensively in an undifferentiated state, therefore they can provide an unlimited source of many tissue types. ${ }^{8,13}$ Human ESCs have great potential to differentiate and are able to form cells of all three embryonic germ layer lineages. ${ }^{9}$ The transplantation of pluripotent stem cells, including ESCs, to supply new neurons to the infarcted brain region of stroke patients is one mechanism to decrease ongoing degenerative processes. The cells can replace the dead neural tissue in the infarction area. ESCs can be prompted to differentiate into neural progenitor cells by using several methods. ESC-derived neural cells can survive in brain stroke lesioned areas, and then differentiate into mature neurons. ${ }^{11,14}$

Other source of stem cells, which are part of a specific organ system that only differentiate into appropriate phenotypes for tissues in specific organs, are called ASCs and are found in post-natal tissues. ASCs display significant variation, and sometimes some tissues contain more than one type of ASC. ${ }^{8,15}$ ASCs may be a good choice for stroke therapy because they secrete various bioactive substances into the infarct area, which may be associated with enhancement of neurogenesis and angiogenesis. ${ }^{11,15}$ Mesenchymal stem cells (MSCs) are one type of ASCs that have been used for most clinical trials, which suggest they may have good potential in stroke therapy. ${ }^{16}$

\section{Mesenchymal Stem Cell}

MSCs are a multipotent type of self-renewing cells that produce different daughter cells when implanted into the appropriate tissue network. ${ }^{16}$ MSCs can be isolated from bone marrow, umbilical cord and adipose tissue, and they express the specific mesenchymal markers CD105, CD90, and CD73. ${ }^{17,18}$ The other characteristics of MSCs is the ability to differentiate into osteocytes, chondrocytes, and adipocytes. ${ }^{17}$ MSCs secrete various bioactive substances, including trophic factors and extracellular vesicles into the brain lesion ${ }^{15}$, to enhance neurogenesis, angiogenesis, and synaptogenesis. In addition, MSCs play a role in reducing inflammation, reducing scarring, normalizing the micro/ metabolic environment profiles, and possibly replacing damaged cells in various brain diseases. ${ }^{4,15,16,19}$ Thus, MSCs have great potential in the treatment of stroke. In addition, MSCs are generally derived from autologous tissue, which is precluded from ethical controversy surrounding stem cells. MSCs are easily cultured in vitro, has weak immunogenicity (because it expresses few HLA class I and no HLA class II molecules) and allows for good safety. Thus, MSCs are safely suggested as an ideal seed cell in the treatment of ischemic stroke. ${ }^{4,17}$ 


\section{Mechanisms of Action for MSC}

MSCs contribute to the treatment of cerebral ischemia through multiple mechanisms, such as cell migration ${ }^{20}$, angiogenesis, prevention of apoptosis, increased proliferation, neurotrophic factor secretion, neural circuit reconstruction and immunomodulation. They also reduce scar formation by reducing reactive glycogenesis. ${ }^{21,22}$ In particular, MSCs provide a neuroprotective effect through cell migration to the infarct region, where they subsequently secrete neurotrophic factors. ${ }^{21}$ These neurotrophic factors will then activate endogenous cellular repair programs in the infarct region. ${ }^{3}$

MSCs exhibit the feature for homing and repair the injured nerve tissue is because its ability to migrate and survive in the ischemic hemisphere, creating a microenvironment conducive for cell survival and regeneration., ${ }^{4,23}$ MSCs migration into the infarct area is through the stromal cell-derived factor-1 (SDF-1)/C$\mathrm{X}-\mathrm{C}$ chemokine receptor (CXCR)-4 signalling pathway. The pathway serve as the homing signal for MSCs. ${ }^{24}$ $\mathrm{SDF} 1 / \mathrm{C}-\mathrm{X}-\mathrm{C}$ motif chemokine ligand (CXCL)-12 is a small molecule which belong to $\mathrm{CXC}$ chemokine family. ${ }^{25}$ Hypoxia-responsive transcription factor hypoxia inducible factor 1 (HIF-1) will induce microglia and astrocytes to secrete SDF-1 in the infarct area after stroke. ${ }^{23}$ SDF-1 will interact with CXCR-4, the physiological receptor for SDF1, expressed by MSCs on the cell surface and inside it.The SDF-1/CXCR-4 interaction causes the MSCs migration into the infarct area. ${ }^{21}$ This mechanism involves in the process of tissue repair in both exogenous and endogenous fashions. ${ }^{22}$ due to the activation of CXCR-4 which triggered multiple signals for cell survival, chemotaxis, proliferation, apoptosis, and differentiation. ${ }^{25}$

in vitro studies have shown that MSCs secrete at several types of trophic factors after co-culturing with cortical neurons under hypoxic conditions. Some of the tropic factor of MSCs have neuroprotective effect in the early stages of transplantation and also induce parenchymal cells in host tissue. ${ }^{4,17,26}$ These neurotrophic factors trigger functional recovery after stroke through decreased apoptosis and inflammation as well as an endogenous proliferation of stem cells and progenitor cells in peri-infarcted tissues, angiogenesis, and neurogenesis. ${ }^{21}$ This neurotrophic factors has a target to activate the endogenous repair of neuroprogenitor cells (NPS) in the subventricular zone (SVZ). ${ }^{3}$ Neutrophic factor produce by MSC includes brain-derived neurotrophic factor (BDNF), fibroblast growth factor (FGF)-2, glial cell-derived neurotrophic factor (GDNF), neurotrophin (NT)-3 an other that are listed in Table 1 with their fuctions.

During the process of neuron repair in ischemic stroke, microglia will activate and produce pro-inflammatory cytokines. This is a microglia 1 (M1) phenotype mechanism associated with tissue destruction. MSCs will secreted paracrine factors to inhibit the activity of M1 phenotype microglia and induce the activation of the microglia 2 (M2) phenotype which is the anti-inflammatory phenotype. ${ }^{12}$

Tabel 1. Trophic factor and their function. . $^{3,26}$

\begin{tabular}{ll}
\hline \multicolumn{1}{c}{ Trophic Factor } & \multicolumn{1}{c}{ Function } \\
\hline Basic fibroblast growth factor (bFGF) & $\begin{array}{l}\text { Angiogenesis } \\
\text { Anti-apoptotic } \\
\text { Anti-fibrotic }\end{array}$ \\
\hline Hepatocyte growth factor (HGF) & Anti-apoptotic \\
Anti-fibrotic
\end{tabular}

\section{Neural Stem Cell}

Neural Stem Cell (NSCs) are multipotent stem cells of the central nervous system $(\mathrm{CNS})^{29}$, particularly in the brain's SVZ and the sub-granular zone (SGZ). ${ }^{28}$ It has three features as stem cells: the ability to self-renew, to differentiate into neural lineage cells, and to regenerate neural tissue. These neural lineages are neurons, astrocytes, and oligodendrocytes. ${ }^{30}$ When differentiating, NSCs commit to specific lineage, from progenitor cells into neuronal and glial cells. ${ }^{31}$ To characterize the cells, cell markers can be used for identification. The NSC antibody markers and the lineage restricted precursor are listed in Table 2. 
Table 2. Antibody markers used for NSC immunophenotyping. ${ }^{30}$

\begin{tabular}{lclccc}
\hline \multirow{2}{*}{$\begin{array}{c}\text { Neural Stem } \\
\text { Cell }\end{array}$} & \multirow{2}{*}{ Reference } & \multicolumn{5}{c}{ Lineage Restricted Precursor } \\
\cline { 2 - 6 } Integrin $\alpha 1 \beta 5$ & $(32)$ & A2B5 & Reference & Neurons & Reference \\
\hline CD15 & $(37-39)$ & CD44 & $(43-36)$ & PSA-NCAM & $(35,37)$ \\
\hline CD24 & $(42,43)$ & CD3 & $(33)$ & MAP-2 & $(41)$ \\
\hline CD133 & $(37,39,44)$ & NG2 & $(45)$ & Doublecortin & $(41)$ \\
\hline CXCR4 & $(39)$ & O1 & $(46)$ & & \\
\hline NOTCH1 & $(47)$ & GFAP & $(41)$ & & \\
\hline & & O4 & $(41)$ & \\
\cline { 3 - 6 } EGFR1 (EGF) & $(48,49)$ & Gal-c & $(41)$ & $(41)$ \\
\cline { 3 - 6 } & & MBP & & \\
\hline
\end{tabular}

CD: cluster of differentiation; CXCR: C-X-C chemokine receptor; NOTCH1: Notch homolog 1; EGF: epidermal growth factor; EGFR1: EGF receptor-1; NG2: neural/ glial antigen 2; GFAP: glial fibrillary acidic protein; Gal-c: galactocerebroside; MBP: myelin basic protein; PSA-NCAM: polysialylated neural cell adhesion molecule; MAP-2: Microtubule-associated protein-2.

Recent studies of NSCs show that NSCs have potential for future cell therapy. Protocols has been developed to isolate and expand NSCs in vitro, but are difficult to manage due to resource constraints. ${ }^{30}$ Further studies on expanding NSCs are needed in producing cells for therapy.

\section{Mechanism of NSC}

Repairing the brain after stroke using the MSCs had been done and some cases had been reported in the clinicaltrials.gov database. However, these are also reports that the potency of MSCs for neural repair may be limited in patients who have limited numbers of NSCs. ${ }^{11}$ In an ischemic stroke injury, the SVZ niche will be activated so that the proliferation of NSCs will increase to accommodate the injury. The new cells will migrate and differentiate into lineage-specific cell types. ${ }^{14}$ NSCs are able to differentiate into mature neurons to be integrated into neural circuits to recover the lost function. ${ }^{28}$

The repair mechanism involves the integration of cells into the lesion site. NSCs will produce neuroblasts within three days of the stroke. ${ }^{28}$ Neuroblasts from the rostral migratory stream (RMS) will migrate to the olfactory bulb. The neuroblasts will then migrate from the SVZ by a hemophilic mechanism and a vasophilic mechanism (using blood vessels) for locomotion. Migration from RMS is controlled by chemo-repulsion factors Slit1 and Slit2, and by chemo-attraction factors such as netrin, neuregulin, ephrin, and BDNF. Deficiency of polysialyated neural cell adhesion molecules (PSA-NCAM) and $\beta 1$-integrins will result in a decrease in NSC migration. ${ }^{29}$

Differentiation of NSCs will produce neurons, astrocytes and oligodendrocytes. However, only, 20\% of dead tissue will be replaced. The $80 \%$ of the newly formed neurons will die. ${ }^{28}$ This is because the microenvironment in ischemic strokes is unsuitable for the survival of endogenous NSC-derived neurons and often, cells will differentiate into glia. ${ }^{50}$ In order for NSCs to perform effective repair, they induce a neuro-inflammatory response to activate astrocytes, microglia and angiogenesis by releasing chemokines and growth factors such as CXCL12, erythropoietin, mitochondrial pyruvate carrier (MPC)-1, angiopoietin-1, BDNF, GDNF, and vascular endothelial growth factor (VEGF) ${ }^{28}$ The BDNF, nerve growth factor (NGF), GDNF and ciliary neurotrophic factor (CNTF) are responsible for prevention of neuronal apoptosis and formation of glial scars. ${ }^{50}$

\section{Approach for MSC Transdifferentiation to NSC}

in vitro and in vivo studies have shown that MSCs have the capability to transform into neural lineage cells, including neurons, glia, and Schwann cells ${ }^{51}$, and also into vascular endothelial cells. ${ }^{22}$ This ability is classified as trans-differentiation, which describes the ability to change between committed cell lineage of differentiation. in vitro differentiation of MSCs is done by adding stimulants ${ }^{52}$, such as growth factors into the culture media. ${ }^{51}$ Growth 
factors such as epidermal growth factor (EGF), basic fibroblast growth factor (bFGF) $)^{54}$, NGF, interferon- $\gamma$, and chemical agents, such as retinoic acid (RA) $)^{53}$, dimethylsulfoxide (DMSO), and $\beta$-mercaptoethanol (BME) could induce the differentiation of MSCs into NSCs. ${ }^{31}$ Forskolin and 3-isobutyl-1-methylxanthine (IBMX), platelet derived growth factor homodiner B (PDGF-BB), heregulin B27, could also induce the differentiation of MSCs into NSCs. ${ }^{54,55}$

Woodbury, et al., reported that using chemical agents shows that after several hours nearly $80 \%$ of the MSCs turned into neuronal morphology cells. These cells were confirmed using immunofluorescence staining with nestin after 5 hours of treatment. ${ }^{56}$ Nestin is an intermediate filament protein expressed in neuroepithelial neuronal precursor stem cells. The expression of nestin will decrease with neuronal maturation. Other markers such as TrkA, Tau, neuron-specific enolase (NSE), glial fibrillary acidic protein (GFAP), neuron-specific nuclear protein $(\mathrm{NeuN})$ are also used to confirm these neural lineage cells. ${ }^{53,56,57}$

\section{Stem Cell Therapy for Stroke Using MSC and NSC}

Stem cell transplantation for stroke had been performed more than 15 years ago. However, to date, there is no optimal model yet. Early studies of stem cell therapy for treating strokes were based on replacing neural cells that were lost as a result of ischemic brain injury. These cells can be neuronal, astrocytic, oligodendroglial, or endothelial in phenotype. ${ }^{58}$ The success of stem cell therapy is influenced by the type of stem cell, cell doses, and route of administration. ${ }^{3}$

Many publications has been reported the used of MSCs in stroke therapy. Paracrine effect is believed to be the most important mechanism in improvement of neurological function. This include the action of enchancing the angiogenesis and neurogenesis as an immunomodulation and anti-inflamation molecule. The paracrine effect will activate because of the infiltation of neutrophils and macrophages in blood brain barrier. ${ }^{1}$ However, some paper also reported that intravenous administration of MSC show no improvement in stroke patient. ${ }^{19,22}$ This might due to the limited number of NSCs to replace the injured neurons.

Administration of MSCs and MSC-derived-NSCs could be a new approach to treat neurological disorder such as stroke. ${ }^{59}$ Both stem cells will have different mechanism to in the treatment. MSC-derived-NSCs will serves as the exogenous NSC to replace the injured neurons. Evidence also suggesting that NSCs secrete neurotrophic factors that protect dysfunctional motor neurons. Other neurotropic factor such as NGF and neurotrophin-3, GDNF, and bovine dermal fibroblasts (BDF) will increase the survival of dopaminergic neurons, therefore the neurons will survive and new neurons and synapses will grow. ${ }^{60}$

\section{Conclusion}

Stem cell therapy for repairing the nervous system after an ischemic stroke has been conducted several years ago. NSCs will replace the dead cell after stroke, however it is not easy to to isolate NSC due to invasive procedure. We hope that the in vitro MSC trans-differentiated NSC could be used as an alternative for external source of cell in regenerative therapy.

\section{References}

1. Stapf C, Mohr JP. Ischemic Stroke Therapy. Annu Rev Med. 2002; 53: 453-75

2. Marler JR, Tilley BC, Lu M, Brott TG, Lyden PC, Grotta JC, et al. Early Stroke Treatment Associated with Better Outcome: The NINDS rt-PA Stroke Study. Neurology. 2000; 55(11): 1649-55.

3. Corey S, Ghanekar S, Sokol J, Zhang JH, Borlongan CV. An Update on Stem Cell Therapy for Neurological Disorders: Cell Death Pathways as Therapeutic Targets. Chin Neurosurg J. 2017; 3: 4. doi: 10.1186/s41016-016-0071-2.

4. Li G, Yu F, Lei T, Gao H, Li P, Sun Y, et al. Bone Marrow Mesenchymal Stem Cell Therapy in Ischemic Stroke: Mechanisms of Action and Treatment Optimization Strategies. Neural Regen Res. 2016; 11(6): 1015-24.

5. Sart S, Ma T, Li Y. Preconditioning Stem Cells for In Vivo Delivery. BioResearch. 2014; 3(4): 137-49.

6. Mozaffarian D, Benjamin EJ, Go AS, Arnett DK, Blaha MJ, Cushman M, et al. Heart Disease and Stroke Statistics--2015 Update: A Report from the American Heart Association. Circulation. 2015; 131(4): e29-322.

7. Yudiarto F, Machfoed M, Darwin A, Ong A, Karyana M, Siswanto. Indonesia Stroke Registry (S12.003). Neurology. 2014; 82(Suppl10): S12.003.

8. Levy YS, Stroomza M, Melamed E, Offen D. Embryonic and Adult Stem Cells as A Source for Cell Therapy in Parkinson's Disease. J Mol Neurosci. 2004; 24(3): 353-86.

9. Damayanti S, Triana R, Chouw A, Dewi NM. Is Stem Cell a Curer or an Obstruction? Mol Cell Biomed Sci. 2017; 1(1): 17-27.

10. Xu W, Zheng J, Gao L, Li T, Zhang J, Shao A. Neuroprotective Effects of Stem Cells in Ischemic Stroke. Stem Cells Int. S2017; 2017: 4653936. doi: 10.1155/2017/4653936.

11. Bang OY, Kim EH, Cha JM, Moon GJ. Adult Stem Cell Therapy for Stroke: Challenges and Progress. J Stroke. 2016; 18(3): 256-66.

12. Hsuan YCY, Lin CH, Chang CP, Lin MT. Mesenchymal Stem Cellbased Treatments for Stroke, Neural Trauma, and Heat Stroke. Brain Behav. 2016; 6(10): e00526. doi: 10.1002/brb3.526.

13. Daadi MM, Steinberg GK. Manufacturing Neurons from Human 
Embryonic Stem Cells: Biological and Regulatory Aspects to Develop a Safe Cellular Product for Stroke Cell Therapy. Regen Med. 2009; 4(2): 251-63.

14. Meamar R, Dehghani L, Ghasemi M, Khorvash F, Shaygannejad V. Stem Cell Therapy in Stroke: A Review Literature. Int J Prev Med. 2013; 4(Suppl 2): S139-46.

15. Gonzalez MA, Bernad A. Characteristics of Adult Stem Cells. Adv Exp Med Biol. 2012; 741: 103-20.

16. Maria Ferri AL, Bersano A, Lisini D, Boncoraglio G, Frigerio S, Parati E. Mesenchymal Stem Cells for Ischemic Stroke: Progress and Possibilities. Curr Med Chem. 2016; 23(16): 1598-608.

17. Anderson JD, Pham MT, Contreras Z, Hoon M, Fink KD, Johansson HJ, et al. Mesenchymal Stem Cell-based Therapy for Ischemic Stroke. Chin Neurosurg J. 2016; 2(1): 36. doi: 10.1186/s41016-0160053-4.

18. Glenn JD, Whartenby KA. Mesenchymal Stem Cells: Emerging Mechanisms of Immunomodulation and Therapy. World J Stem Cells. 2014; 6(5): 526-39.

19. Seo JH, Cho SR. Neurorestoration Induced by Mesenchymal Stem Cells: Potential Therapeutic Mechanisms for Clinical Trials. Yonsei Med J. 2012; 53(6): 1059-67.

20. Aggarwal S, Pittenger MF. Human Mesenchymal Stem Cells Modulate Allogeneic Immune Cell Responses. Blood. 2005; 105(4): 1815-22.

21. Toyoshima A, Yasuhara T, Date I. Mesenchymal Stem Cell Therapy for Ischemic Stroke. Acta Med Okayama. 2017; 71(4): 263-8.

22. Ikegame Y. Among Mesenchymal Stem Cells: for the Best Therapy After Ischemic Stroke. Stem Cell Res Ther. 2013; 4(1): 9. doi: 10.1186/scrt157.

23. Yu Q, Liu L, Lin J, Wang Y, Xuan X, Guo Y, et al. SDF-1 $\alpha /$ CXCR4 Axis Mediates The Migration of Mesenchymal Stem Cells to The Hypoxic-Ischemic Brain Lesion in A Rat Model. Cell J Yakhteh. 2015; 16(4): 440-7.

24. Sullivan R, Duncan K, Dailey T, Kaneko Y, Tajiri N, Borlongan CV. A Possible New Focus for Stroke Treatment - Migrating Stem Cells. Expert Opin Biol Ther. 2015; 15: 949-58.

25. Cencioni C, Capogrossi MC, Napolitano M. The SDF-1/CXCR4 Axis in Stem Cell Preconditioning. Cardiovasc Res. 2012; 94(3): 400-7.

26. Tate CC, Fonck C, McGrogan M, Case CC. Human Mesenchymal Stromal Cells and their Derivative, SB623 Cells, Rescue Neural Cells via Trophic Support following in Vitro Ischemia Human Mesenchymal Stromal Cells and their Derivative, SB623 Cells, Rescue Neural Cells via Trophic Support following in Vitro Ischemia. Cell Transplant. 2010; 19(8): 973-84.

27. Collawn SS, Patel S. Adipose-Derived Stem Cells, their Secretome, and Wound Healing. J Cell Sci Ther. 2014; 5(3): 165. doi: 10.4172/2157-7013.1000165.

28. Martínez-Garza DM, Cantú-Rodríguez OG, Jaime-Pérez JC, Gutiérrez-Aguirre CH, Góngora-Rivera JF, Gómez-Almaguer D. Current State and Perspectives of Stem Cell Therapy for Stroke. Med Univ. 2016; 18(72): 169-80.

29. Magnon C, Lucas D, Frenette PS. Trafficking of Stem Cells. In: Filippi MD, Geiger H. Stem Cell Migration. New York: Humana Press; 2011. p. 3-24.

30. Cruz JO-D la, Ayuso-Sacido A. Neural Stem Cells from Mammalian Brain: Isolation Protocols and Maintenance Conditions. In: Neural Stem Cells and Therapy. London: IntechOpen; 2012. p.1-29.

31. Arien-Zakay H, Lecht S, Nagler A, Lazarovici P. Human Umbilical Cord Blood Stem Cells: Rational for Use as a Neuroprotectant in Ischemic Brain Disease. Int J Mol Sci. 2010; 11(9): 3513-28.
32. Yoshida N, Hishiyama S, Yamaguchi M, Hashiguchi M, Miyamoto Y, Kaminogawa S, et al. Decrease in Expression of Alpha 5 Beta 1 Integrin during Neuronal Differentiation of Cortical Progenitor Cells. Exp Cell Res. 2003; 287(2): 262-71.

33. Maric D, Maric I, Chang YH, Barker JL. Prospective Cell Sorting of Embryonic Rat Neural Stem Cells and Neuronal and Glial Progenitors Reveals Selective Effects of Basic Fibroblast Growth Factor and Epidermal Growth Factor on Self-renewal and Differentiation. J Neurosci Off J Soc Neurosci. 2003; 23(1): 240-51.

34. Nunes MC, Roy NS, Keyoung HM, Goodman RR, McKhann G, Jiang L, et al. Identification and Isolation of Multipotential Neural Progenitor Cells from the Subcortical White Matter of the Adult Human Brain. Nat Med. 2003; 9(4): 439-47.

35. Windrem MS, Roy NS, Wang J, Nunes M, Benraiss A, Goodman R, et al. Progenitor Cells Derived from the Adult Human Subcortical White Matter Disperse and Differentiate as Oligodendrocytes Within Demyelinated Lesions of the Rat Brain. J Neurosci Res. 2002; 69(6): 966-75.

36. Wright AP, Fitzgerald JJ, Colello RJ. Rapid Purification of Glial Cells Using Immunomagnetic Separation. J Neurosci Methods. 1997; 74(1): 37-44.

37. Panchision DM, Chen H-L, Pistollato F, Papini D, Ni H-T, Hawley TS. Optimized Flow Cytometric Analysis of Central Nervous System Tissue Reveals Novel Functional Relationships among Cells Expressing CD133, CD15, and CD24. Stem Cells Dayt Ohio. 2007; 25(6): 1560-70.

38. Capela A, Temple S. LeX/ssea-1 is Expressed by Adult Mouse CNS Stem Cells, Identifying Them as Nonependymal. Neuron. 2002; 35(5): 865-75.

39. Corti S, Locatelli F, Papadimitriou D, Donadoni C, Del Bo R, Fortunato F, et al. Multipotentiality, Homing Properties, and Pyramidal Neurogenesis of CNS-derived LeX(ssea-1)+/CXCR4+ Stem Cells. FASEB J Off Publ Fed Am Soc Exp Biol. 2005; 19(13): $1860-2$.

40. Liu Y, Han SSW, Wu Y, Tuohy TMF, Xue H, Cai J, et al. CD44 Expression Identifies Astrocyte-restricted Precursor Cells. Dev Biol. 2004; 276(1): 31-46.

41. Siebzehnrubl FA, Vedam-Mai V, Azari H, Reynolds BA, Deleyrolle LP. Isolation and Characterization of Adult Neural Stem Cells. Methods Mol Biol Clifton. 2011; 750: 61-77.

42. Murayama A, Matsuzaki Y, Kawaguchi A, Shimazaki T, Okano H. Flow Cytometric Analysis of Neural Stem Cells in the Developing and Adult Mouse Brain. J Neurosci Res. 2002; 69(6): 837-47.

43. Rietze RL, Valcanis H, Brooker GF, Thomas T, Voss AK, Bartlett PF. Purification of A Pluripotent Neural Stem Cell from the Adult Mouse Brain. Nature. 2001; 412(6848): 736-9.

44. Uchida N, Buck DW, He D, Reitsma MJ, Masek M, Phan TV, et al. Direct Isolation of Human Central Nervous System Stem Cells. Proc Natl Acad Sci USA. 2000; 97(26): 14720-5.

45. Aguirre AA, Chittajallu R, Belachew S, Gallo V. NG2-expressing Cells in the Subventricular Zone are Type C-like Cells and Contribute to Interneuron Generation in the Postnatal Hippocampus. J Cell Biol. 2004; 165(4): 575-89.

46. Duncan ID, Paino C, Archer DR, Wood PM. Functional Capacities of Transplanted Cell-Sorted Adult Oligodendrocytes. Dev Neurosci. 1992; 14(2): 114-22.

47. Johansson CB, Momma S, Clarke DL, Risling M, Lendahl U, Frisén J. Identification of A Neural Stem Cell in the Adult Mammalian Central Nervous System. Cell. 1999; 96(1): 25-34. 
48. Ciccolini F, Mandl C, Hölzl-Wenig G, Kehlenbach A, Hellwig A. Prospective Isolation of Late Development Multipotent Precursors Whose Migration is Promoted by EGFR. Dev Biol. 2005; 284(1): $112-25$.

49. Pastrana E, Cheng LC, Doetsch F. Simultaneous Prospective Purification of Adult Subventricular Zone Neural Stem Cells and Their Progeny. Proc Natl Acad Sci USA. 2009; 106(15): 6387-92.

50. Drago D, Cossetti C, Iraci N, Gaude E, Musco G, Bachi A, et al. The Stem Cell Secretome and Its Role in Brain Repair. Biochimie. 2013; 95(12): 2271-85.

51. Ghasemi N, Razavi S. Transdifferentiation Potential of Adiposederived Stem Cells into Neural Lineage and Their Application. J Histol Histopathol. 2014; 1(1): 12. doi: 10.7243/2055-091X-1-12.

52. Krabbe C, Zimmer J, Meyer M. Neural Transdifferentiation of Mesenchymal Stem Cells - A Critical Review. APMIS. 2005;113(11-12): 831-44.

53. Mareschi K, Novara M, Rustichelli D, Ferrero I, Guido D, Carbone E, et al. Neural Differentiation of Human Mesenchymal Stem Cells: Evidence for Expression of Neural Markers and Eag K+ Channel Types. Exp Hematol. 2006; 34(11): 1563-72.

54. Shahbazi A, Safa M, Alikarami F, Kargozar S, Asadi MH, Joghataei
MT, et al. Rapid Induction of Neural Differentiation in Human Umbilical Cord Matrix Mesenchymal Stem Cells by cAMPelevating Agents. Int J Mol Cell Med. 2016; 5(3): 167-77.

55. Moore TJ, Abrahamse H. Neuronal Differentiation of Adipose Derived Stem Cells: Progress So Far. Int J Photoenergy. 2014; 2014: e827540. doi: 10.1155/2014/827540.

56. Woodbury D, Schwarz EJ, Prockop DJ, Black IB. Adult Rat and Human Bone Marrow Stromal Cells Differentiate into Neurons. J Neurosci Res. 2000; 61(4): 364-70.

57. Sanchez-Ramos J, Song S, Cardozo-Pelaez F, Hazzi C, Stedeford T, Willing A, et al. Adult Bone Marrow Stromal Cells Differentiate into Neural Cells in Vitro. Exp Neurol. 2000; 164(2): 247-56.

58. Misra V, Ritchie MM, Stone LL, Low WC, Janardhan V. Stem Cell Therapy in Ischemic Stroke. Neurology. 2012; 79(13 Suppl 1): S207-12.

59. Andres RH, Choi R, Steinberg GK, Guzman R. Potential of Adult Neural Stem Cells in Stroke Therapy. Regen Med. 2008; 3(6): 893905.

60. Baraniak PR, McDevitt TC. Stem Cell Paracrine Actions and Tissue Regeneration. Regen Med. 2010; 5(1): 121-43. 